\title{
THE EVOLVING LANDSCAPE OF ACUTE MYELOID LEUKEMIA TREATMENT.
}

\section{SHORT COMMUNICATION}

\author{
Lucia Mariano da Rocha Silla \\ Hospital de Clínicas de Porto Alegre - Centro de Processamento Celular Avançado (CPCA) \\ Correspondence to: dralucia.silla@gmail.com
}

Acute Myeloid Leukemia (AML) is a fatal disease. At least two thirds of the patients die of AML in the first few years of diagnosis, and most of them in the first year. [1]

There are several mutations involved in the pathogenesis of this heterogeneous disease and some impact survival; [2] all result in the abnormal functioning of a component of a molecular pathway involved in cell cycle activity or apoptosis. Some of these latter mutations are targetable, and new target drugs are been tested or already used in clinical practice, with objective impact on disease severity and overall survival. $[3,4]$

Additionally, there are several new drugs either targeting leukemia microenvironment molecules, or its biophysical aspects, intent to changing the molecular milieu of the malignant cell surroundings; some targeting the malignant cell metabolism or oncoprotein metabolites, and yet some epigenetic drugs aiming to chromatin stabilization and control of malignant genes transcription activity. [5] These drugs might, in selected cases, be utilized in association with one another or to a less toxic and very effective low dose chemotherapy, or yet as monotherapy for the very old and ill population. Complete and partial remission (CR or PR) or stable disease is seen in this scenario and ways to maintain it are been tested and used.

Technics to measure disease burden evolved in the last decades leading to the understanding of measurable residual disease and its impact in AML prognosis. Measurable tumor burden before stem cell transplant (SCT) is alone a risk factor for relapse and disease progression after transplant, usually leading to death in the first few months. [6-7] By regularly measuring residual disease, relapse can be detected in an asymptomatic patient and preemptive thera- py can be putted in place. Usually, in the majority of SCT centers, the first clinical intervention is lowering immunosuppression or withdrawing it completely, sometimes followed by donor lymphocyte infusion (DLI), hoping to harness the graft versus leukemia effect (GVL), frequently and unfortunately, accompanied by graft versus host disease (GVHD). However, GVHD is not particularly prevalent or severe after DLI when utilized in the prophylactic setting according to a recent metanalysis. [8]

Emerging data on the above-mentioned target drugs, are increasingly robust, and better quality of live seems to be one outstanding aspect. Side effects of molecular target drugs are mild and manageable.

For many decades, intensive chemotherapy followed by SCT in intermediate and adverse risks disease is the backbone of AML treatment; [9] however, most patients are elderly and dye during or following intensive treatment, $[10,11]$ since they frequently have comorbidities and develop several complications during the myeloid and lymphoid ablated periods. Most of them are not eligible for stem cell transplantation (SCT), and once AML relapses, as pointed above, survival is very poor.

The understanding of the graft versus leukemia (GVL) effect and its importance for SCT success, [12] as well as the good results obtained with DLI in obtaining CR or disease control (8) have brought into attention the role that immune cells have in leukemia's control and cure.

SCT for AML should be preferentially myeloablative in order to decrease tumor burden in those with high-risk leukemia and good performance status. Myeloablative strategies by killing abnormal and normal leucocytes, modify bone marrow microenvironment. Steven Rosenberg et al. [13] have suggested that myeloablative strategies can affect the 
general microenvironment that becomes rich in myeloid and lymphoid colony-factors and stimulating molecules.

Pre-clinical and clinical studies with adoptive transfer of lymphocytes have proven beneficial effects in cancer. $[14,15]$ However, the Vito effect have to be taken into consideration in immunotherapy. The patients' resident lymphocytes or leukocytes can kill the incoming cells preventing the infused cells in vivo activation, either in blood circulation or at the tissue level. According to Rosenberg, myeloablation and/or lympho-ablation is the optimum scenario for adoptive immunotherapy efficacy. [13]

Systemically infused in vitro expanded lymphocytes, once into the circulation, can sense the increased concentration of activating molecules, migrate toward the origin of its production and home to that environment, unleashing its anti-tumor and immunomodulatory activity.

The benefic role of CAR-T cells on B cell malignancies is indisputable and much have been learned from it; one key aspect is that the in vivo CAR-T cells expansion/activation appears to be related with a better anti-tumor effect. CAR-T cell therapy has also brought into attention cytokine release syndrome (CRS) as well as its unexpected CNS effects, opening a new path to better understanding in vivo immune system function, its pros and cons, and how to clinically manage it. [15] The utilization of anti-PD1 receptor or its ligand monoclonal antibodies have proved that exhausted lymphocytes can be reactivated in the tumor microenvironment - making the case for autologous adoptive immunotherapy, with significant results been seen in the solid tumor scenario particularly in lung cancer. [16] Taken together, these mounting data support immunotherapy trials for the treatment of cancer.

Natural killer cells have repeatedly been shown to have antitumor, [17] and antileukemia effect [18-20], and it appears related to GVL effect as its early emergency after SCT myeloablation is correlated with PDS and OS. [21] Since pioneering studies of Velardi's group, [22] in Italy, in a population of AML patients predominantly in second $C R$ and submitted to a $T$ cell depleted haploidentical SCT, GVL's mediated NK cells anti-leukemia effect have been recognized.

NK cells are innate lymphocytes bearing natural cytotoxic receptors that recognize molecular patterns (common to all effector's cells) and several other receptors to ligands on altered cells' surfaces. Killer Immunoglobulin like Receptors [23] were first described in and are predominantly express by NK cells. Their main role is to inhibit NK cell activation, although some are actually able to promote it. These latter are expressed by individuals belonging to NK cell B Haplotype-type, since NK cells from these individuals are characterized by expressing an excess of KIR activating receptors.

Been able to recognize one's self HLA class I or a normally expressed HLA class I antigen, renders NK cells disabled to kill a normal cell. In summary, NK cell activation, either to develop cytotoxicity or secrete immune molecules, is the result of balancing the amount and activation of activator and inhibitory receptors.

NK cells are CD3 negative and CD56 positive cells. Most of our peripheral blood circulating NK cells also express CD16, a FC receptor to immunoglobulin that promotes ADCC. For many years $\mathrm{CD} 56^{+} \mathrm{CD} 16^{+++} \mathrm{NK}$ cells were considered the NK cell mature, functional phenotype. [24] However, tissue resident or occasional tissue transiting NK cells express a variable, apparently tissue dependent phenotype, in the lung, as an example $75 \%$ of tissue resident NK cells are CD$56^{\text {bright }}$ with variable low or no expression of CD16. $[25,26]$

Innate lymphocytes are meant to bridging innate and adaptive immunity. [27] As for NK cells, it has been shown they modulate $T$ cell response either by IFN-gamma or through GM-CSF secretion since it has an important role in promoting $T$ cells and Dendritic Cells (DC) maturation and activation, and in the case of DC, also migration and antigen presentation untimely promoting adaptive immune reaction. [28]

It is possible that NK cells are capable of bouncing between its cytotoxic (CD56 dim/CD16 bright) and secretive (CD56 bright/CD16 $\left.{ }^{\text {dim}}\right)$ phenotype as well as in between its shades. In vitro exposition of NK cells to certain ligands can render them CD56 bright/CD16 $6^{\text {bright }}$ [29], suggesting that there is potential for in vivo phenotype shifting according to the molecular milieu. The fact that tissue's NK cells are predominantly of the secretive phenotype calls the attention for its immunomodulation importance and role. Hence, the desirable NK cell effect is also secretion of several cytokines and chemokines: active molecules that modulate immune adaptive system effectors, with higher specificity and less harmful for the organism.

In a recent Phase 1 trial of double bright (CD56 brigth/ CD16 $6^{\text {bright }) ~ N K ~ c e l l ~(D B-N K) ~ f o r ~ r e f r a c t o r y ~ o r ~ r e l a p s e d ~}$ AML (R/R-AML), we were able to document the persistence of the infused DB-NK cells, however, in 
most responding patients $\mathrm{T}$ cell recovery predominated; we also showed that NK cell predominant in vivo expansion didn't necessary correlated with leukemia response (submitted manuscript); these results could suggest that antileukemic NK cell cytotoxic and immunomodulation activity results in an adaptive immunity response. In this phase 1 trial including a rather ill population of patients, cryopreserved, DB-NK cells infusions up to $10^{7}$ cells/kg per infusion, in a total of 6 infusions, was well tolerated and its emergent anti leukemia or anti-microbial effects were clinically manageable. No CSR, fever, or serious adverse events were related with infusion, and in spite of some very ill patients been included, none of them died or clinically deteriorated because of NK cell adoptive immunotherapy. We treated 13 patients of whom 5 had primary refractory disease and 9 had relapsed or were refractory to SCT. The median line of previous treatments was 5 , and they all received DB-NK cells with active disease. Seventy eight percent of the patients got either into CR (50\%) or CRi (only one patient) or had partial response. OS for responders and non-responders were 344 and 254 days, respectively. PFS was 132 days for all and 199 days for responders. We were able to show that DB-NK cell adoptive immunotherapy is not only feasible and safe, but also effective in such an advance AML group of patients, increasing OS in spite of disease burden or localization as we also documented CNS responses. [30]

According to the MRD studies, SCT associated GVL anti-AML effect alone, cannot overcome high tumor burden, suggesting that adoptive immunotherapy ("graft") versus leukemia effect, so to speak, is probable more effective in a situation of minimal measurable disease, or preferentially, minimal residual disease (MRD).

The combination of target drugs, with or without low dose chemotherapy and immunotherapy should be pursued for augmenting good quality survival and possibly, cure in AML.

\section{REFERENCES}

1. Institute NC. Surveillance, Epidemiology and End Results (SEER) Stat Facts: Leukemia-Acute Myeloid Leukemia; 2018. https://seer.cancer.gov/statfacts/html/amyl.html: Accessed August 2020.

2. Döhner H, Estey E, Grimwade D, Amadori S, Appelbaum FR, Büchner T, et al. Diagnosis and management of AML in adults: 2017 ELN recom- mendations from an international expert panel. Blood. 2017v.129, n.4, p.424-47.

3. Stone RM, Larson RA, Döhner H. Midostaurin in FLT3-Mutated Acute Myeloid Leukemia. N Engl J Med. 2017, v.377, n.19,p.1903.

4. Richard-Carpentier G, DiNardo CD. Single-agent and combination biologics in acute myeloid leukemia. Hematology Am Soc Hematol Educ Program. 2019n.1, p.48-56.

5. Bates SE. Epigenetic Therapies for Cancer. N Engl J Med. 2020;383(7):650-63.

6. Furtado F, Beltrame M, Souto E, Ikoma-Colturato $M$. Minimal residual disease in acute myeloid leukemia. Journal of Bone Marrow Transplantation and Cellular Therapy. 2020;(5).

7. Ravandi F, Pierce S, Garcia-Manero G, Kadia T, Jabbour E, Borthakur G, et al. Salvage Therapy Outcomes in a Historical Cohort of Patients With Relapsed or Refractory Acute Myeloid Leukemia. Clin Lymphoma Myeloma Leuk. 2020.

8. Poonsombudlert K, Kewcharoen J, Prueksapraopong C, Limpruttidham N. Prophylactic donor lymphocyte infusion for relapse prevention: a meta-analysis. Jpn J Clin Oncol. 2020v.50, n.6, 661-70.

9. Koreth J, Schlenk R, Kopecky KJ, Honda S, Sierra J, Djulbegovic BJ, et al. Allogeneic stem cell transplantation for acute myeloid leukemia in first complete remission: systematic review and meta-analysis of prospective clinical trials. JAMA. 2009;301(22):2349-61.

10. Oran B, Weisdorf DJ. Survival for older patients with acute myeloid leukemia: a population-based study. Haematologica. 2012v.301, n.22,p.1916-24.

11. Appelbaum FR, Gundacker $H$, Head DR, Slovak $\mathrm{ML}$, Willman $\mathrm{CL}$, Godwin JE, et al. Age and acute myeloid leukemia. Blood. 2006;107(9):3481-5.

12. Dickinson AM, Norden J, Li S, Hromadnikova I, Schmid C, Schmetzer H, et al. Graft-versus-Leukemia Effect Following Hematopoietic Stem Cell Transplantation for Leukemia. Front Immunol. 2017v.8, p.96.

13. Dudley ME, Yang JC, Sherry R, Hughes MS, Royal $\mathrm{R}$, Kammula U, et al. Adoptive cell therapy for patients with metastatic melanoma: evaluation of intensive myeloablative chemoradiation preparative regimens.J Clin Oncol. 2008v.26, n.32, p.233-9. 
14. Chester C, Fritsch K, Kohrt HE. Natural Killer Cell Immunomodulation: Targeting Activating, Inhibitory, and Co-stimulatory Receptor Signaling for Cancer Immunotherapy. Front Immunol. 2015v.6, p.:601.

15. Park JH, Rivière I, Gonen $M$, Wang $X$, Sénéchal $B$, Curran KJ, et al. Long-Term Follow-up of CD19 CAR Therapy in Acute Lymphoblastic Leukemia. N Engl J Med. 2018v.378, n.5, p.449-59.

16. Facchinetti F, Di Maio M, Tiseo M. Adding PD-1/ PD-L1 Inhibitors to Chemotherapy for the FirstLine Treatment of Extensive Stage Small Cell Lung Cancer (SCLC): A Meta-Analysis of Randomized Trials. Cancers (Basel). 2020v.12, n.9, p.

17. Dahlberg Cl, Sarhan D, Chrobok M, Duru AD, Alici E. Natural Killer Cell-Based Therapies Targeting Cancer: Possible Strategies to Gain and Sustain Anti-Tumor Activity. Front Immunol. 2015v.6, p.

18. Miller JS, Soignier Y, Panoskaltsis-Mortari A, McNearney SA, Yun GH, Fautsch SK, et al. Successful adoptive transfer and in vivo expansion of human haploidentical NK cells in patients with cancer. Blood. 2005v.105, n.8, p.3051-7.

19. Romee R, Rosario $M$, Berrien-Elliott MM, Wagner JA, Jewell BA, Schappe T, et al. Cytokine-induced memory-like natural killer cells exhibit enhanced responses against myeloid leukemia. Sci Transl Med. 2016;v.8, n.357, p.357ra123.

20. Vela $M$, Corral $D$, Carrasco $P$, Fernández $L$, Valentín J, González B, et al. Haploidentical IL-15/41BBL activated and expanded natural killer cell infusion therapy after salvage chemotherapy in children with relapsed and refractory leukemia. Cancer Lett. 2018v. 422, p.107-17.

21. Hattori N, Saito B, Sasaki Y, Shimada S, Murai S, Abe $M$, et al. Status of Natural Killer Cell Recovery in Day 21 Bone Marrow after Allogeneic Hematopoietic Stem Cell Transplantation Predicts Clinical Outcome. Biol Blood Marrow Transplant. 2018v.24, n.9,p.1841-7.
22. Ruggeri L, Capanni M, Casucci M, Volpi I, Tosti A, Perruccio K, et al. Role of natural killer cell alloreactivity in HLA-mismatched hematopoietic stem cell transplantation. Blood. 1999;94(1):333-9.

23. Vitale M, Cantoni C, Della Chiesa M, Ferlazzo G, Carlomagno S, Pende D, et al. An Historical Overview: The Discovery of How NK Cells Can Kill Enemies, Recruit Defense Troops, and More. Front Immunol. 2019v.10, p.1415.

24. Caligiuri MA. Human natural killer cells. Blood. 2008v. 112, n.3, p.461-9.

25. Hashemi E, Malarkannan S. Tissue-Resident NK Cells: Development, Maturation, and Clinical Relevance. Cancers (Basel). 2020,v.12, n.6,p.

26. Yang C, Siebert JR, Burns R, Gerbec ZJ, Bonacci $B$, Rymaszewski $A$, et al. Heterogeneity of human bone marrow and blood natural killer cells defined by single-cell transcriptome. Nat Commun. 2019v.10. n. 1, p.3931.

27. Crome SQ, Lang PA, Lang KS, Ohashi PS. Natural killer cells regulate diverse $T$ cell responses. Trends Immunol. 2013;34(7):342-9.

28. Clavijo-Salomon MA, Salcedo R, Roy $S$, das Neves RX, Dzutsev A, Sales-Campos H, et al. Human NK cells prime inflammatory DC precursors to induce Tc17 differentiation. Blood Adv. 2020v.4,n.16, p.3990-4006.

29. Denman CJ, Senyukov VV, Somanchi SS, Phatarpekar PV, Kopp LM, Johnson JL, et al. Membrane-bound IL-21 promotes sustained ex vivo proliferation of human natural killer cells. PLOS One. 2012v.7, n.1,e30264.

30. Silla L, Valim V, Pezzi A, Weber C, Soares T, Burin $M$, et al. Phase I study of adoptive transfer of haploidentical expanded NK cells Relapse/ Refractory AML. European Blood and Marrow Transplantation (EBMT): Oral Presentation; 2020. 